\title{
DESCRIPTION AND PERFORMANCE OF A NOVEL CONCEPT "SINGLE LEVEL" CERAMIC CHIP CARRIER
}

\author{
ANDRE DE KEYSER, CLAUDE DELAUTRE and GUY NAMECHE \\ Sprague Electromag Belgium N.V. Merodestraat 2B-900 Ronse, Belgium
}

(Received November 5, 1981; in final form August 13, 1982)

Two different designs of ceramic chip carriers are discussed. A carrier capable of being hermetically sealed has been developed which uses a glass seal combined with an epoxy bonded chip. A second carrier which does not have hermeticity has also been designed in which the alumina cap is attached to the base with a thermo setting resin. The applicability of these two types is examined.

\section{INTRODUCTION}

Many different styles of ceramic chip carriers "CCC" are currently introduced on the package market. Because of the particular advantages of the CCC concept compared to other packaging techniques, as stressed in the literature on subject, a definite trend exists towards its widespread use in modern hybrids.

This paper deals with a novel CCC concept based upon the following basic features:

- complete freedom of package size and of output connection grid because of the moderate tooling costs involved.

- all thick film technology

- single level low cost epoxy seal or hermetic glass seal.

The CCC package described ideally suits the hybrid manufacturer who faces a wide variety of circuits in the medium scale of $30-70 \mathrm{~K}$ pieces.

\section{TECHNOLOGY DESCRIPTION}

Five different approaches were studied by the Electromag engineering department using the same chip carrier base and alumina cover. The manufacture of the carriers is done in multiple, based upon conventional silk screen printing on a $96 \%$ alumina substrate provided with pre-punched holes. The metallization inside the holes is performed by throughprinting conductive paste. This technique is based on the fact that initially the carrier bases are side by side on a larger substrate. They are separated by breaking along laser scribed lines after the conductor patterns are printed. The scribing passes through the center of the metallized holes as shown in Figure 1.

Two different noble metal pastes are used for printing conductors:

a) an Au conductor for eutectic bonding of the chip and wire bonding.

b) a Pd.Ag conductor for the output metallization along the edges.

The cap is $96 \%$ alumina (see Figure 2). The mechanical requirements imposed on the alumina cap are stringent in order to assure reliable bonding. 


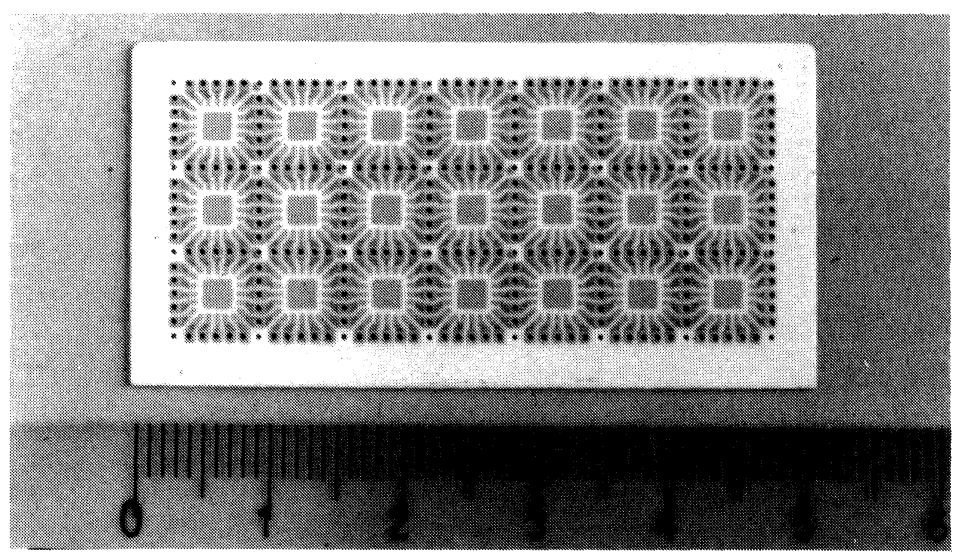

FIGURE 1 Unscribed substrate showing metallized bases and holes.

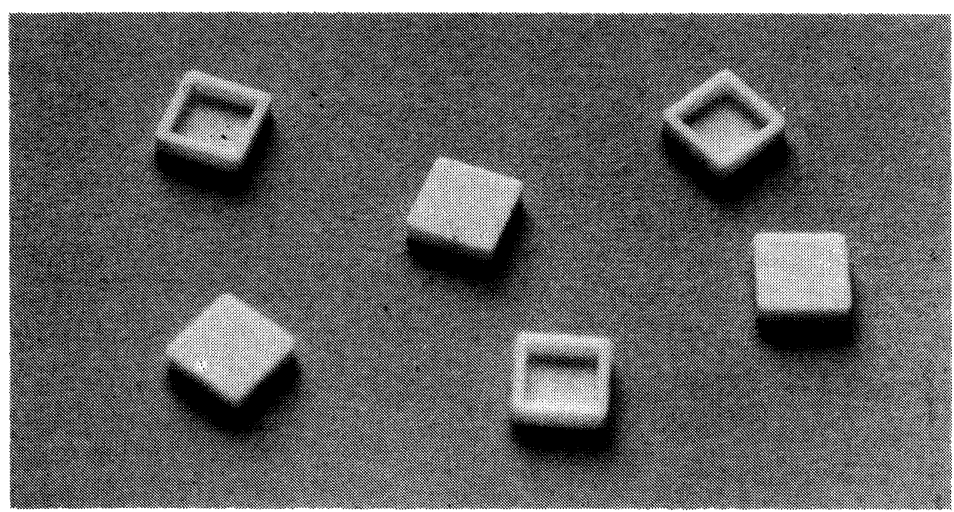

FIGURE 2 Alumina caps for fitting over metallized bases (approx. $5 \mathrm{~mm} \times 5 \mathrm{~mm} \times 1 \mathrm{~mm}$ )

Base and cover are sealed together by means of a thermoset polymer or glass joint. This results in a hermetically sealed single layer ceramic carrier (Figure 3 ).

The five designs are defined in Table I.

A thermoset sealing compound is applied by means of a printing method. Then, base and covers are heated at the curing temperature. During the curing cycle, the two parts are put under constant pressure. For the low melting temperature glass, a particular sealing process is used.

In order to obtain local heating of the substrate, a conductor ring is screened on the backside of the carrier base and used as heating resistance (Figure 4).

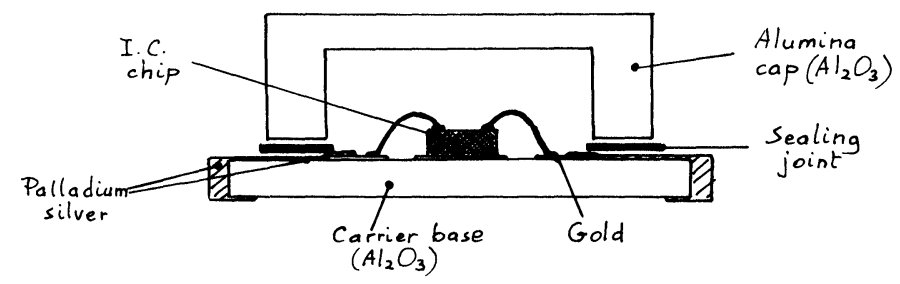

FIGURE 3 Sealed ceramic carrier. 
TABLE I

Design alternatives.

\begin{tabular}{llll}
\hline Alternative & Chip attachment & Wire attachment & Sealing joint \\
\hline A & eutectic $\mathrm{Au}-\mathrm{Si}$ & gold thermosonic & $\begin{array}{l}\text { low melting temperature } \\
\text { glass }\end{array}$ \\
B & thermoset & gold thermosonic & $\begin{array}{l}\text { low melting } \\
\text { temperature glass }\end{array}$ \\
C & thermoset & $\begin{array}{l}\text { aluminium } 1 \% \mathrm{Si} \\
\text { ultrasonic }\end{array}$ & $\begin{array}{l}\text { low melting temperature } \\
\text { glass }\end{array}$ \\
$\mathrm{D}$ & eutectic $\mathrm{Au}-\mathrm{Si}$ & $\begin{array}{l}\text { gold thermosonic } \\
\text { aluminium } 1 \% \mathrm{Si}\end{array}$ & $\begin{array}{l}\text { thermoset } \\
\text { thermoset }\end{array}$ \\
$\mathrm{E}$ & thermoset & $\begin{array}{l}\text { ultrasonic } \\
\end{array}$ &
\end{tabular}

This conductor ring matches the ring of the alumina cap on the front side of the alumina base. An insulation layers is printed over the ring in order to avoid short circuits between the ring and the output metallizations.

The sealing glass paste is screened onto the carrier base. It is applied by means of an offset printing on the alumina cap. Both parts are now fired separately in order to achieve the glazing.

The ceramic cap and the carrier base are then preheated together at a temperature $100^{\circ} \mathrm{C}$ lower than the melting point of the sealing glass. Two suitable probes are applied to the conductor or resistor ring. At the same time they press the base and the cap close together (Figure 5).

After a fixed short preheating time, pulsed electric energy is applied to the resistor ring via the probes. This provides locally an adequate rise in temperature for a long enough period to melt the glass on the base and cover.

By this method the correct sealing bond is made. After switching off the pulse current, the temperature quickly falls below the melting point of the glass and the sealed carrier may be handled without damage during cooling.

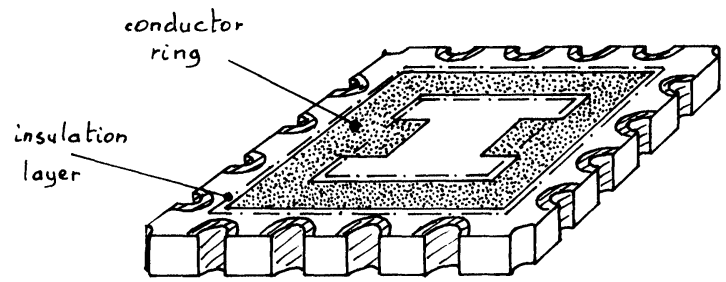

FIGURE 4 Backside of the carrier base.

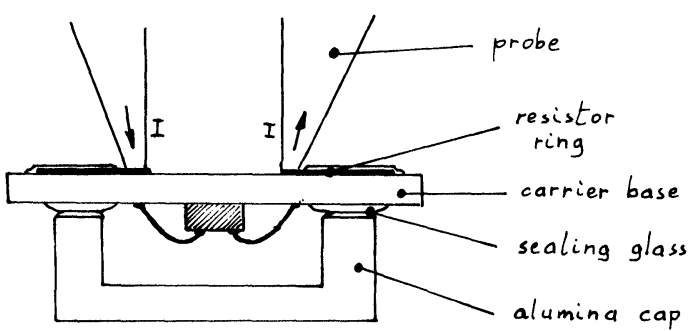

FIGURE 5 Sealing operation. 


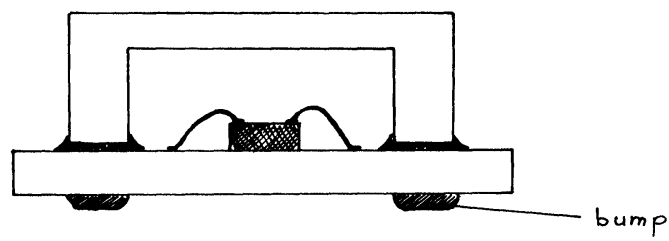

FIGURE 6 Flux removal.

In order to allow flux removal after soldering to the hybrid circuit, four silicone resin bumps are printed on the underside of the carrier (Figure 6).

\section{TEST RESULTS}

The IC chip used for the test was a voltage comparator type 710 .

The following parameters were controlled:

$-V_{\text {io }}$ input offset voltage

$-I_{\text {io }} \quad$ input offset current

$-I_{\text {ib }} \quad$ input bias current

$-\mathbf{A}_{\mathrm{vol}}$ voltage gain

TABLE II

Sealing and environmental test results. Legend: + : non significant drift - : catostrophic drift.

\begin{tabular}{|c|c|c|c|c|c|}
\hline Version & A & B & $\mathrm{C}$ & D & $\mathrm{E}$ \\
\hline Sealing & - & - & + & + & + \\
\hline $\begin{array}{l}\text { Thermal shocks MIL-Std }-883 \text { method } 1011-2 \\
\left(20 \text { cycles }-55^{\circ} \mathrm{C} /+125^{\circ} \mathrm{C} \text {, direct transition in liquids) }\right.\end{array}$ & & & + & + & + \\
\hline Storage at $+125^{\circ} \mathrm{C}, 250 \mathrm{hrs}$ & & & + & + & + \\
\hline Storage at $-55^{\circ} \mathrm{C}, 250 \mathrm{hrs}$ & & & + & + & + \\
\hline $\begin{array}{l}\text { Load humidity under bias } 672 \text { hours } \\
-85^{\circ} \mathrm{C} 85 \% \text { RH minimum dissipation }\end{array}$ & & & + & + & + \\
\hline Damp heat cycling IEC $68-2-4$ test $\mathrm{Da}$ & & & + & + & + \\
\hline
\end{tabular}

Versions $\mathbf{A}$ and $\mathbf{B}$ failed after sealing due to intermetallic reaction gold-aluminium on the chip during the sealing cycle.

After sealing and soldering, gross and fine leak were performed with a maximum leak rate of $10^{-8} \mathrm{cc} / \mathrm{sec}$.

\section{APPLICATIONS}

Applications of CCC's are illustrated on the flow chart of Figure 7. The two necessary conditions to use these packaging techniques are as follows: when I.C. chips with less than $300 \mathrm{~mW}$ dissipation each have to be used and when an extended degree of miniaturization is required.

Incidentally, hermetically conjointly with relatively low cost is required, the glass seal version is the most suitable solution. If hermeticity is not required, while "SO ... style" plastic packages are not available, thermoset seal version is to be recommended. 


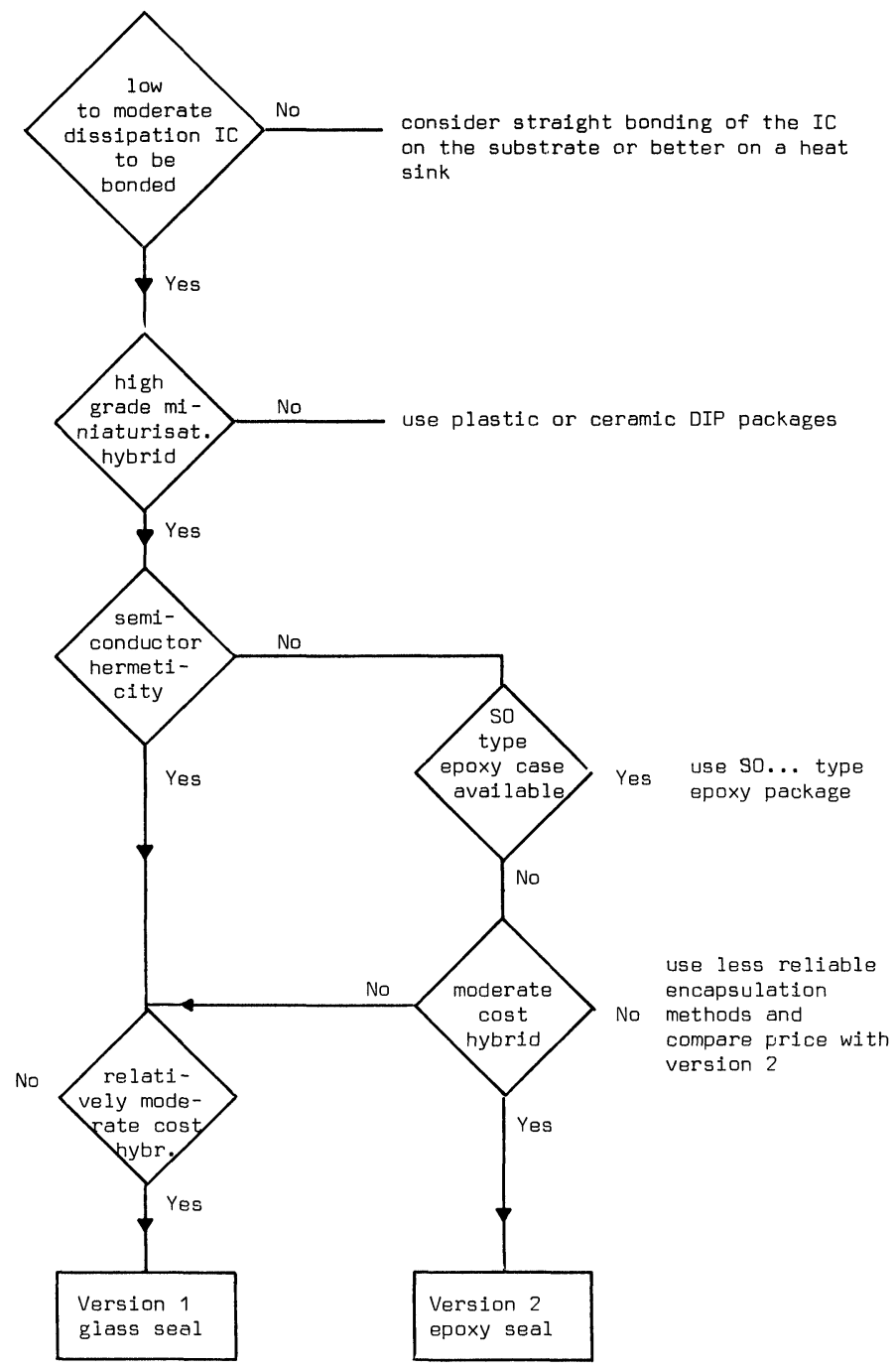

FIGURE 7 Applications of CCC's

\section{CONCLUSIONS}

Finally two different design approaches were selected:

1) the hermetic grade CCC for which we would use a glass seal combined with epoxy bonding of the chip consistant with an ultrasonic bonding of aluminium wires.

2) the second approach, without any hermeticity pretence, where we achieve the bonding of the alumina cap by means of a thermoset seal. Two combinations are possible i.e. eutectic chip bonding combined with thermosonic gold wire attachment, or epoxy glued chips with aluminium wires and ultrasonic bonding. 

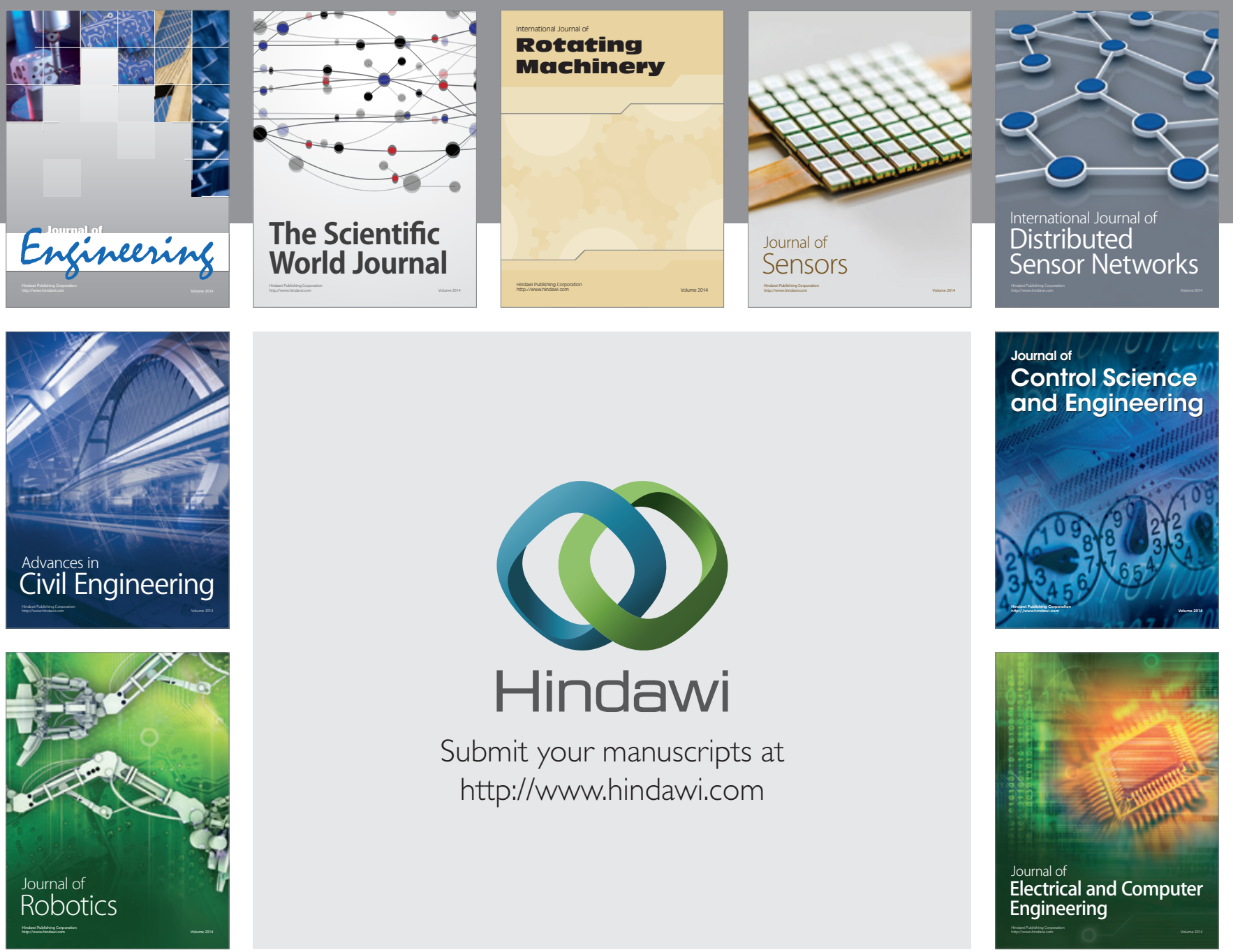

Submit your manuscripts at

http://www.hindawi.com
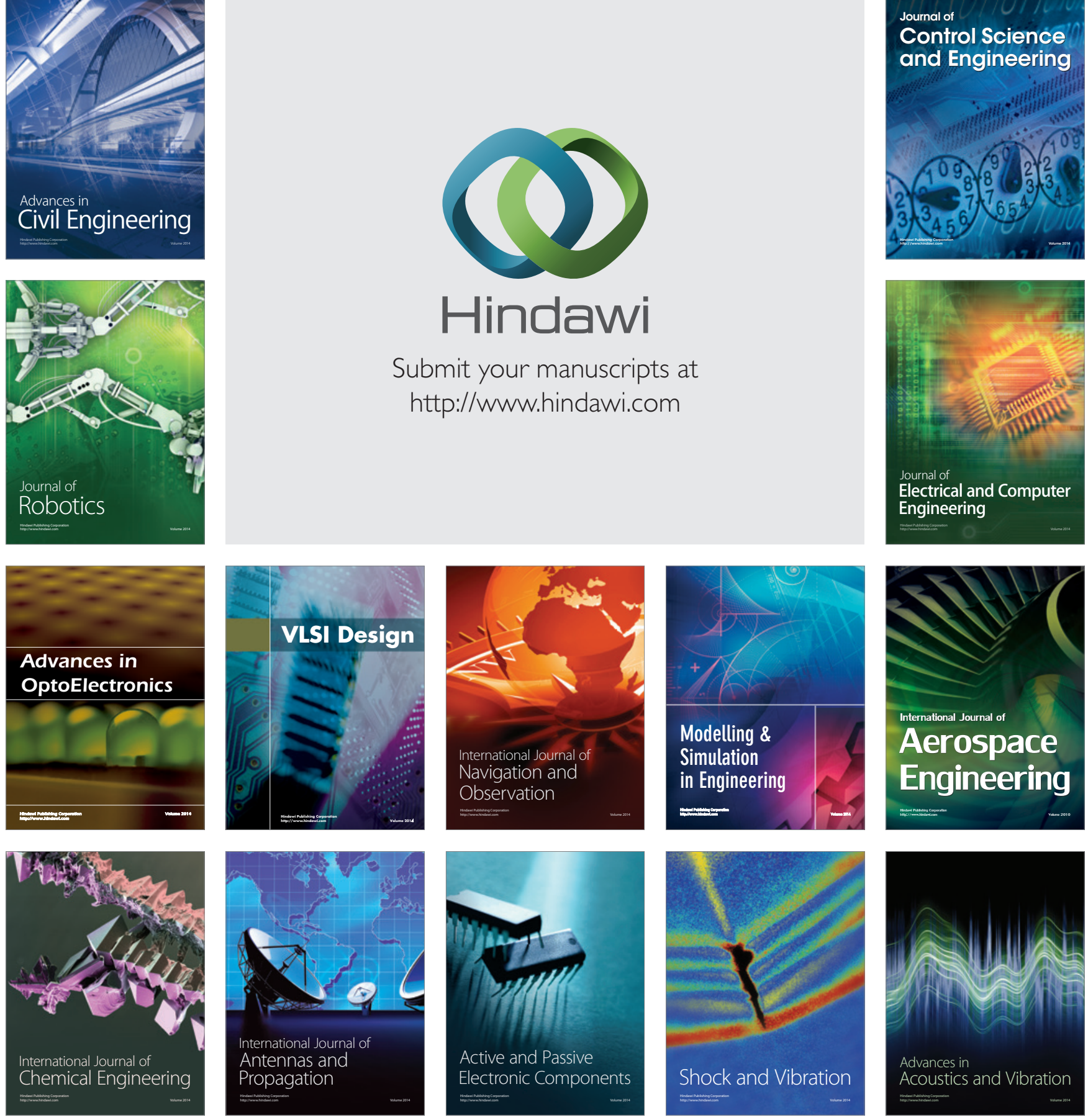